\title{
Glycated albumin and the risk of micro- and macrovascular complications in subjects with Type 1 Diabetes
}

Hye-jin Yoon ${ }^{1,2 \dagger}$, Yong-ho Lee ${ }^{1,2 \dagger}$, So Ra Kim², , Tyler Hyungtaek Rim², ${ }^{2,}$ Eun Young Lee ${ }^{1,2}$, Eun Seok Kang ${ }^{1,2}$, Bong-Soo Cha ${ }^{1,2}$, Hyun Chul Lee ${ }^{1,2}$ and Byung-Wan Lee ${ }^{1,2^{*}}$

\begin{abstract}
Background: We investigated the relationship between the glycemic indices glycated albumin (GA) and glycated hemoglobin $\left(\mathrm{HbA}_{1 c}\right)$ and the progression of diabetic vascular complications [diabetic nephropathy (DN) and carotid artery atherosclerosis (CAA)] in subjects with type 1 diabetes (T1D).

Methods: A total of 154 participants with a median follow-up of 2.8 years were enrolled in this retrospective longitudinal study. We recruited T1D subjects who had regularly measured urine albumin-creatinine ratios and estimated glomerular filtration rates, as well as tested $\mathrm{HbA}_{1 c}$ and GA levels consecutively every 3 or 6 months. A subgroup of 54 subjects was measured repeated carotid intima-media thickness (IMT).

Results: We classified subjects into the DN progression (Group I; $n=30$ ) with either deteriorated stages of chronic kidney disease $(n=18)$ or albuminuria progression $(n=17)$, and the non-progression (Group $I ; n=124)$. In multiple logistic regression analyses, baseline albuminuria (odds ratio $[\mathrm{OR}]=2.64,95 \%$ confidence interval $[\mathrm{Cl}]=1.03-6.74$ ), mean $\mathrm{GA}$ levels $(\mathrm{OR}=2.03,95 \% \mathrm{Cl}=1.27-3.26)$ were significantly associated with progression of DN. However, there was no association with mean $\mathrm{HbA}_{1 \mathrm{c}}(\mathrm{OR}=0.98,95 \% \mathrm{Cl}=0.62-1.54)$. In a subgroup analysis for follow-up measurements of carotid IMT, age was independently associated with the presence of plaque and the mean IMT. However glycemic indices were not significantly associated with CAA.
\end{abstract}

Conclusions: Mean GA levels were more closely associated with DN progression than mean $\mathrm{HbA}_{1 c}$ in subjects with T1D. However, they were not associated with the CAA.

Keywords: Type 1 diabetes, Glycated albumin, Diabetic nephropathy, Carotid artery atherosclerosis

\section{Introduction}

Current guidelines for glucose monitoring recommend self-monitoring of blood glucose (SMBG) and glycated hemoglobin $\left(\mathrm{HbA}_{1 \mathrm{c}}\right)$ to accurately assess glycemic status and prevent diabetic complications [1,2]. Treatment recommendations for type 1 diabetes (T1D) are largely based on the results of the Diabetes Control and Complications Trial (DCCT) and the follow-up of the DCCT cohort for an additional 8 or 16 years in the Epidemiology of Diabetes Interventions and Complications

\footnotetext{
* Correspondence: bwanlee@yuhs.ac

${ }^{\dagger}$ Equal contributors

'Department of Internal Medicine, Yonsei University College of Medicine, Seoul, South Korea

${ }^{2}$ Severance Hospital, Seoul, Korea, 120-752

Full list of author information is available at the end of the article
}

(EDIC) study [3, 4]. These trials showed that the intensive treatment T1D group had lower $\mathrm{HbA}_{1 \mathrm{c}}$ levels, which reduced the risk of microalbuminuria and decreases in the glomerular filtration rate (GFR), compared to the conventional treatment group $[2,3,5,6]$. Although $\mathrm{HbA}_{1 \mathrm{c}}$ is considered a gold standard measurement for glucose monitoring in patients with diabetes, there is growing evidence regarding the clinical relevance of intermediate-term glycemic index of glycated albumin (GA) for the diagnosis, evaluation for glucose status, and prediction of diabetic complications, particularly in patients with type 2 diabetes (T2D) [7-10]. Recently, Nathan et al. reported the clinical relevance of various glucose biomarkers of short-, intermediate-, and long-term glycemia on micro- and macrovascular complications in 
subjects with T1D. These authors suggested that $\mathrm{HbA}_{1 \mathrm{c}}$ and GA predicted retinopathy and nephropathy to a greater extent than mean blood glucose values, and the combination of both measurements strengthened the association with retinopathy but not with nephropathy [11]. Based on the results of the DCCT/EDIC study [11], we aimed to determine which glycemic index is more closely associated with the progression of diabetic nephropathy (DN), a microvascular complication, and carotid artery atherosclerosis (CAA), a macrovascular complication, in Korean subjects with T1D.

\section{Subjects, materials and methods} Subjects and research design

In this retrospective longitudinal study, we recruited subjects with T1D [12] who were registered in the Severance Hospital Diabetes Registry between August 2009 and December 2013. We used the following inclusion criteria: 1) patients who regularly measured both their spot urine albumin-creatinine ratio (ACR) and kidney function using estimated GFR; and 2) patients who tested $\mathrm{HbA}_{1 \mathrm{c}}$ and GA levels consecutively every 3 or 6 months. The exclusion criteria for this study were patients with non-diabetic kidney disease, end-stage renal disease (ESRD) on dialysis, severe liver disease, pancreatic cancer, hyper or hypothyroidism or acute infectious disease. We classified subjects into two groups: the DN progression group (Group I) and the DN non-progression group (Group II). We defined Group I subjects with deteriorated renal function based on estimated GFR or the advent of albuminuria greater than $30 \mu \mathrm{g} / \mathrm{ml}$ or the progression in albuminuria from microalbuminuria [30-300 $\mu \mathrm{g} / \mathrm{mg}$ ACR] to macroalbuminuria $(>300 \mu \mathrm{g} / \mathrm{mg}, \mathrm{ACR})$. For deteriorated renal function, we adopted six clinically-relevant Chronic kidney disease $(C K D)$ categories $(\geq 90,60-89,45-59$, $30-44,15-29$, or $<15 \mathrm{~mL} / \mathrm{min} / 1.73 \mathrm{~m}^{2}$ ) that were assessed using the chronic kidney disease epidemiology collaboration formula (CKD-EPI) [13]. We also defined impaired renal function as decreased CKD stage. For albuminuria, we applied the conventional definition of microalbuminuria as $30 \mu \mathrm{g} / \mathrm{mg} \leq$ urinary $\mathrm{ACR} \leq 300 \mu \mathrm{g} / \mathrm{mg}$ and macroalbuminuria as ACR $>300 \mu \mathrm{g} / \mathrm{mg}$. In logistic regression analyses, we adhered to the previous definition of microalbuminuria as urinary ACR more than $40 \mu \mathrm{g} / \mathrm{mg}$ [11]. We conducted additional analyses on the progression of CAA to patients who were repeatedly examined for carotid intima-media thickness (IMT). These subjects were classified into the active CAA and inactive CAA groups. The active CAA group was defined as patients with newly developed carotid artery plaque(s) or persistent ones, whereas inactive CAA group included patients with the absence of carotid IMT plaques or regressed plaques. The Presence of retinopathy was confirmed by an ophthalmologist based on funduscopic findings. The Ethics Committee of the Yonsei University College of Medicine approved this study protocol (2013-0917-001).

\section{Laboratory measurements}

Blood samples were collected from patients after overnight fasting. Serum GA levels were determined using an enzymatic method and an albumin-specific proteinase (ketoamine oxidase), albumin assay reagent (LUCICA GA-L, Asahi Kasei Pharma Co., Tokyo, Japan), and a Hitachi 7699 P module auto-analyzer (Hitachi Instruments Service, Tokyo, Japan) [14]. The coefficient of variation $(\mathrm{CV})$ was $1.43 \%$. $\mathrm{HbA}_{1 \mathrm{c}}$ was measured using high-performance liquid chromatography (HPLC) and a Variant II Turbo (Bio-Rad Laboratories, Hercules, CA). The reference intervals of $\mathrm{HbA}_{1 \mathrm{c}}$ were between 4.0 and $6.0 \%$, whereas those of GA were between 11.0 and $16.0 \%$. The averages of $\mathrm{HbA}_{1 \mathrm{c}}$ (mean $\mathrm{HbA}_{1 \mathrm{c}}$ ), GA (mean GA) were determined by taking the sum of every measured value in each individual divided by the number of values obtained throughout the study period.

\section{Measurements of carotid intima-media thickness}

Measurements of IMT in both carotid arteries were described in detail previously [15]. Common carotid arterial ultrasound examinations were conducted by two specialized technicians using an Aloka ProSound ALPHA 10 (HITACHI, Tokyo, Japan) with a $13 \mathrm{MHz}$ linear probe. IMT was defined as the distance between the mediaadventitia interface and the lumen-intima interface. Average IMT was the mean value of computer-based points in the region, and maximal IMT was the IMT value at the maximal point of the region. Plaques were defined according to the Mannheim consensus [16], in which a plaque is diagnosed when the vessel wall thickness was $>1.5 \mathrm{~mm}$ or when the vessel wall appeared to be at least $0.5 \mathrm{~mm}$, or $50 \%$ thicker, than the surrounding wall.

\section{Statistical analyses}

All statistical analyses were performed using PASW statistics software (version 20.0; SPSS Inc., Chicago, IL). Continuous variables are described as the mean \pm standard deviation (SD) or the median (interquartile range) based on results from Kolmogorov-Smirnov tests. Categorical data are expressed as the number (n) with percentages. Statistical comparisons between groups with and without DN progression were performed using MannWhitney $U$ tests or $\chi^{2}$ tests, which are non-parametric statistical methods. Multivariate logistic regression analyses were used to estimate multiple correlations between DN progression and clinical and laboratory risk factors. We used receiver operating characteristic (ROC) curve analyses, estimating the area under the curve (AUC) with $95 \%$ confidence intervals $(\mathrm{CI})$, to compare GA levels and 
$\mathrm{HbA}_{1 \mathrm{c}}$. P values $<0.05$ were considered significant. In subgroup analyses, we determined the variables that were associated with carotid artery plaques or atherosclerosis progression using multiple linear regression analyses. Logistic regression power calculation was carried out using PASS software version 13.0.10 (NCSS statistical Software, Kaysville, UT).

\section{Results}

\section{Characteristics of the Study Participants}

A total of 154 participants (69 men and 85 women; mean age, $46 \pm 15$ years) with a median follow-up period of 2.8 years were enrolled in this study. The numbers of subjects that progressed from microalbuminuria to macroalbuminuria and exhibited deterioration of CKD stage were 18 (11.7\%) and 17 (11\%), respectively. Based on these results, we classified subjects into the progressed DN group (Group I; $\mathrm{n}=30$ ) and the nonprogressed DN group (Group II; $\mathrm{n}=124$ ). Table 1 shows the demographic and laboratory characteristics of the subjects. Age, gender, and body mass indices (BMI) were similar between the two groups. The prevalence of hypertension and the use of anti-hypertensive medications did not significantly differ between groups. Group I had a significantly longer diabetic duration [12.0 (10.0-18.0) vs. $8.0(3.0-15.0)$ years, $\mathrm{P}=0.004$ ] and higher proportion of retinopathy (70 \% vs. $46 \%, \mathrm{P}=0.018$ ) compared to Group II. At baseline, estimated GFR (91.7 \pm 20.3

Table 1 Demographic and laboratory characteristics of patients

\begin{tabular}{|c|c|c|c|c|}
\hline & $\begin{array}{l}\text { All } \\
(n=154)\end{array}$ & $\begin{array}{l}\text { Group I } \\
\text { DN progression } \\
(\mathrm{n}=30)\end{array}$ & $\begin{array}{l}\text { Group II } \\
\text { DN non-progression } \\
(\mathrm{n}=124)\end{array}$ & $\mathbf{P}$ \\
\hline \multicolumn{5}{|l|}{ Demographics } \\
\hline Age (years) & $46 \pm 15$ & $50 \pm 15$ & $45 \pm 16$ & 0.135 \\
\hline Male Sex, n (\%) & $69(45)$ & $11(37)$ & $58(47)$ & 0.414 \\
\hline BMI $\left(\mathrm{kg} / \mathrm{m}^{2}\right)$ & $22.6 \pm 3.3$ & $23.2 \pm 3.5$ & $22.4 \pm 3.3$ & 0.256 \\
\hline Obesity, n (\%) & $30(19)$ & $8(27)$ & $22(18)$ & 0.306 \\
\hline Duration of diabetes (years) & $10.0(3.0-15.0)$ & $12.0(10.0-18.0)$ & $8.0(3.0-15.0)$ & 0.004 \\
\hline Retinopathy, n (\%) & $78(51)$ & $21(70)$ & $57(46)$ & 0.018 \\
\hline Hypertension, n (\%) & $31(20)$ & $9(30)$ & $22(18)$ & 0.202 \\
\hline ARB or ACEI use, n (\%) & $49(32)$ & $11(37)$ & $38(31)$ & 0.663 \\
\hline Statin use, n (\%) & $54(35)$ & $15(50)$ & $39(31)$ & 0.056 \\
\hline \multicolumn{5}{|l|}{ Glycemic indices } \\
\hline mean GA (\%) & $24.4(21.5-29.0)$ & $29.3(22.8-34.7)$ & $24.0(21.0-27.5)$ & 0.004 \\
\hline mean $\mathrm{HbA}_{1 \mathrm{c}}(\%)$ & $8.7 \pm 1.6$ & $9.0 \pm 1.4$ & $8.7 \pm 1.7$ & 0.088 \\
\hline \multicolumn{5}{|l|}{ Renal function indices } \\
\hline Baseline ACR ( $\mu \mathrm{g} / \mathrm{mg})$ & $17.8(7.2-71.1)$ & $47.3(11.5-136.1)$ & $14.6(6.0-41.2)$ & 0.004 \\
\hline Follow-up ACR ( $\mu \mathrm{g} / \mathrm{mg})$ & $13.8(7.5-77.9)$ & $134.7(51.7-766.2)$ & $10.6(6.8-29.2)$ & $<0.001$ \\
\hline Baseline eGFR (mL/min/1.73 m²) & $97.1 \pm 22.5$ & $91.7 \pm 20.3$ & $98.4 \pm 22.9$ & 0.079 \\
\hline Follow-up eGFR (mL/min/1.73 m²) & $95.1 \pm 26.0$ & $73.9 \pm 28.7$ & $100.4 \pm 22.4$ & $<0.001$ \\
\hline \multicolumn{5}{|l|}{ Baseline CKD status } \\
\hline Stage 1 & $98(64)$ & $17(57)$ & $81(65)$ & 0.565 \\
\hline Stage 2 & $48(31)$ & $12(40)$ & $36(29)$ & \\
\hline Stage 3 and 4 & $8(5)$ & $1(3)$ & $7(6)$ & \\
\hline \multicolumn{5}{|l|}{ Biochemistry profiles } \\
\hline Albumin (g/dL) & $4.2 \pm 0.4$ & $4.1 \pm 0.5$ & $4.3 \pm 0.4$ & 0.106 \\
\hline Total cholesterol (mg/dL) & $162.0(145.0-194.0)$ & $171.5(149.0-195.8)$ & $162.0(144.0-193.5)$ & 0.423 \\
\hline Triglyceride (mg/dL) & $79.0(60.0-113.5)$ & $90.5(71.8-118.5)$ & $77.0(57.0-114.0)$ & 0.109 \\
\hline HDL-cholesterol (mg/dL) & $57.0 \pm 15.9$ & $55.0 \pm 13.7$ & $57.5 \pm 16.4$ & 0.669 \\
\hline LDL-cholesterol (mg/dL) & $95.5 \pm 34.9$ & $97.6 \pm 31.3$ & $95.0 \pm 35.8$ & 0.495 \\
\hline
\end{tabular}

Continuous variables were described as median (quartiles) or mean \pm SD. N (\%) for categorical variables

$B M I$ body mass index; $A R B$ angiotensin II receptor blocker, $A C E I$ angiotensin-converting enzyme inhibitor, $A C R$ albumin-creatinine ratio, eGFR estimated glomerular filtration rate, $C K D$ chronic kidney disease 
vs. $\left.98.4 \pm 22.9 \mathrm{ml} / \mathrm{min} / 1.73 \mathrm{~m}^{2}, \mathrm{P}=0.079\right)$ and $\mathrm{ACR}[47.3$ (11.5-136.1) vs. 14.6 (6.0-41.2) $\mu \mathrm{g} / \mathrm{mg}, \mathrm{P}=0.004]$ differed between the groups without and with significance, respectively. However, serum creatinine levels [0.8 (0.6-0.9) vs. $0.8(0.7-0.9) \mathrm{mg} / \mathrm{dL}, \mathrm{P}=0.864$ ] were the same in the two groups. Although mean $\mathrm{HbA}_{1 \mathrm{c}}$ levels $(9.0 \pm 1.4$ vs. $8.7 \pm 1.7 \%, P=0.088$ ) were not significantly different, the mean GA levels [29.3 (22.8-34.7) vs. 24.0 (21.0$27.5) \%, P=0.004$ ] were significantly higher in Group I.

\section{Independent Association of Diabetic Nephropathy Progression with Glycemic Indices and Risk Variables for Chronic Kidney Disease}

In univariate logistic regression analyses, DN progression was used as a dependent factor, and the variables for mean glycemic indices and risk factors for CKD were entered. The risk of progression of DN was $35 \%$ higher in subjects with a prolonged duration of diabetes and as duration increased per 5years $(\mathrm{OR}=1.35,95 \%$ CI 1.04$1.75, \mathrm{P}=0.023)$. Higher baseline levels of albuminuria $(\mathrm{OR}=3.29,95 \% \mathrm{CI} 1.44-7.48, \mathrm{P}=0.005)$ and mean $\mathrm{GA}$ levels $(\mathrm{OR}=1.73,95 \% \mathrm{CI} 1.19-2.50, \mathrm{P}=0.004)$ were also significantly associated with $\mathrm{DN}$ progression. However, mean $\mathrm{HbA}_{1 \mathrm{c}}$ levels $(\mathrm{OR}=1.24,95 \%$ CI $0.85-1.81$, $\mathrm{P}=0.265)$ were not significantly related to the progression of DN. Moreover, hypertension, CKD stages, and lipid profiles at baseline were not significantly related to DN progression in this study (Fig. 1).

\section{Glycated albumin predicted the Progression of Diabetic Nephropathy}

Based on the results in Fig. 1, multiple logistic regression analyses were performed to predict the progression of DN (Table 2). For multiple logistic regression analyses, we used four statistical models with different glycemic variables: GA levels and $\mathrm{HbA}_{1 \mathrm{c}}$. In model 1 , we entered age, duration per 5years, baseline albuminuria, obesity $\left(\mathrm{BMI} \geq 25 \mathrm{~kg} / \mathrm{m}^{2}\right)$, hypertension, baseline CKD stage, and mean GA level. The duration of diabetes $(\mathrm{OR}=1.44$, $95 \% \mathrm{CI} 1.01-2.07, \mathrm{P}=0.047)$, baseline albuminuria ( $\mathrm{OR}=$ 2.63, $95 \%$ CI 1.03-6.73, P = 0.043), and mean GA level $(\mathrm{OR}=2.02,95 \% \mathrm{CI} 1.28-3.17, \mathrm{P}=0.002)$ were significantly associated with the progression of DN. In model 2 with mean $\mathrm{HbA}_{1 \mathrm{c}}$, $\mathrm{DN}$ progression did not independently correlate with mean $\mathrm{HbA}_{1 \mathrm{c}}(\mathrm{OR}=1.21,95 \%$ CI 0.79-1.85, $\mathrm{P}=0.390$ ). To investigate the effects of both serum GA levels and $\mathrm{HbA}_{1 \mathrm{c}}$ on $\mathrm{DN}$ progression, we entered mean GA and mean $\mathrm{HbA}_{1 \mathrm{c}}$ as independent glycemic variables in model 3. Mean GA levels (OR $=2.03,95 \%$ CI 1.27-3.26, $\mathrm{P}=0.003$ ) remained its significance in predicting the progression of $\mathrm{DN}$, whereas mean $\mathrm{HbA}_{1 \mathrm{c}}(\mathrm{OR}=0.98,95 \% \mathrm{CI}$ $0.62-1.54, \mathrm{P}=0.918$ ) did not. In terms of retinopathy, duration of diabetes and albuminuria were significant determinants for predicting retinopathy at baseline (data not shown). However, neither mean levels of GA nor $\mathrm{HbA}_{1 \mathrm{c}}$ was associated with the presence of retinopathy at baseline (data not shown).

Using ROC curve analyses, we calculated the AUC of glycemic indices (mean $\mathrm{GA}$ and mean $\mathrm{HbA}_{1 \mathrm{c}}$ ) for predicting DN progression (Fig. 2). Mean GA levels showed a larger AUC $(\mathrm{AUC}=0.668,95 \% \mathrm{CI} 0.55-0.78, \mathrm{P}=$ 0.004) compared to mean $\mathrm{HbA}_{1 \mathrm{c}}$ ( $\mathrm{AUC}=0.601,95 \% \mathrm{CI}$ $0.49-0.71, P=0.088)$. The AUC of mean GA levels was statistically significant.

\section{Association of Carotid artery atherosclerosis with Glycemic Indices and Cardiovascular Risk Factors}

Of the 154 patients with T1D, 54 subjects had repeated carotid IMT data with a mean 2.9 year follow-up. Subjects were classified into the active CAA group $(n=22)$

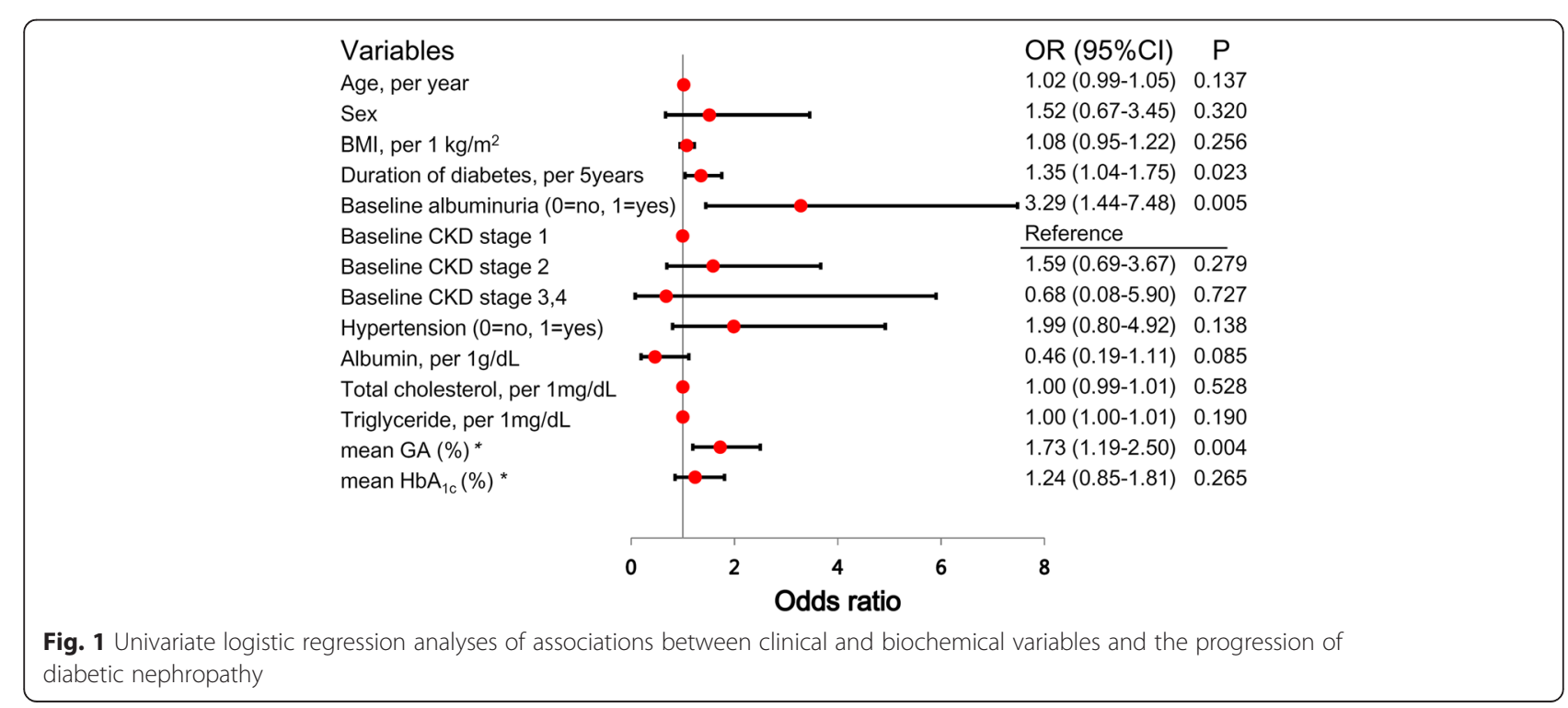


Table 2 Multiple logistic regression models for associations between clinical and biochemical variables and the progression of diabetic nephropathy in a total of 154 subjects with T1D

\begin{tabular}{|c|c|c|c|c|c|c|c|c|c|}
\hline \multirow[b]{2}{*}{ Variables } & \multicolumn{3}{|c|}{$\begin{array}{l}\text { Model } 1 \\
\left(R^{2}=0.28\right)\end{array}$} & \multicolumn{3}{|c|}{$\begin{array}{l}\text { Model } 2 \\
\left(R^{2}=0.20\right)\end{array}$} & \multicolumn{3}{|c|}{$\begin{array}{l}\text { Model } 3 \\
\left(R^{2}=0.28\right)\end{array}$} \\
\hline & OR & $95 \% \mathrm{Cl}$ & $\mathbf{P}$ & OR & $95 \% \mathrm{Cl}$ & $\mathbf{P}$ & OR & $95 \% \mathrm{Cl}$ & $\mathbf{P}$ \\
\hline Age, per year & 1.03 & $0.99-1.07$ & 0.132 & 1.03 & $0.99-1.06$ & 0.188 & 1.03 & $0.99-1.07$ & 0.136 \\
\hline Obesity ( $0=$ no, 1 = yes $)$ & 1.92 & $0.64-5.78$ & 0.243 & 1.95 & $0.69-5.55$ & 0.210 & 1.94 & $0.64-5.81$ & 0.242 \\
\hline Duration of diabetes, per 5years & 1.44 & $1.01-2.07$ & 0.047 & 1.28 & $0.92-1.77$ & 0.145 & 1.44 & $1.01-2.07$ & 0.047 \\
\hline Hypertension ( $0=$ no, 1 =yes) & 2.32 & $0.77-6.99$ & 0.134 & 2.09 & $0.79-5.83$ & 0.160 & 2.32 & $0.77-6.98$ & 0.136 \\
\hline Albuminuria at baseline ( $0=$ no, $1=$ yes $)$ & 2.63 & $1.03-6.73$ & 0.043 & 2.86 & $1.16-7.07$ & 0.023 & 2.64 & $1.03-6.74$ & 0.043 \\
\hline Statin use ( $0=$ no, $1=$ yes $)$ & 1.89 & $0.74-4.88$ & 0.186 & 1.49 & $0.59-3.75$ & 0.403 & 1.91 & $0.73-5.01$ & 0.188 \\
\hline \multicolumn{10}{|l|}{ CKD stage at baseline } \\
\hline Stage1 & \multicolumn{3}{|c|}{ Reference } & \multicolumn{3}{|c|}{ Reference } & \multicolumn{3}{|c|}{ Reference } \\
\hline Stage2 & 0.55 & $0.16-1.86$ & 0.338 & 0.71 & $0.23-2.24$ & 0.559 & 0.55 & $0.16-1.86$ & 0.337 \\
\hline Stage 3 and 4 & 0.09 & $0.01-1.30$ & 0.078 & 0.12 & $0.01-1.54$ & 0.103 & 0.09 & $0.01-1.31$ & 0.078 \\
\hline mean GA $(\%)^{*}$ & 2.02 & $1.28-3.17$ & 0.002 & & & & 2.03 & $1.27-3.26$ & 0.003 \\
\hline mean $\mathrm{HbA}_{1 \mathrm{c}}(\%)^{*}$ & & & & 1.21 & $0.79-1.85$ & 0.390 & 0.98 & $0.62-1.54$ & 0.918 \\
\hline
\end{tabular}

CKD chronic kidney disease

${ }^{*} z$-standardization of glycemic indices

and the inactive CAA group $(\mathrm{n}=32)$. Age [56 (50-70) vs. $41(35-48)$ years, $\mathrm{P}<0.001$ ] and triglyceride levels [103.5 (63.8-189.8) vs. $72.5(55.3-89.8) \mathrm{mg} / \mathrm{dL}, \mathrm{P}=$ 0.004 ] were significantly higher in the active CAA group. Compared with the inactive CAA group, the active CAA group showed significantly higher ACR levels at both baseline [28.7 $(9.8-136.1)$ vs. $7.7(4.1-21.5) \mu \mathrm{g} / \mathrm{mg}]$ and follow-up [32.0 (10.0-108.8) vs. $9.1(2.9-24.1) \mu \mathrm{g} / \mathrm{mg}]$, as well as lower estimated GFR at baseline [87.6 (67.4$100.2)$ vs. $\left.103.1(82.9-115.3) \mathrm{mL} / \mathrm{min} / 1.73 \mathrm{~m}^{2}, \mathrm{P}=0.008\right]$

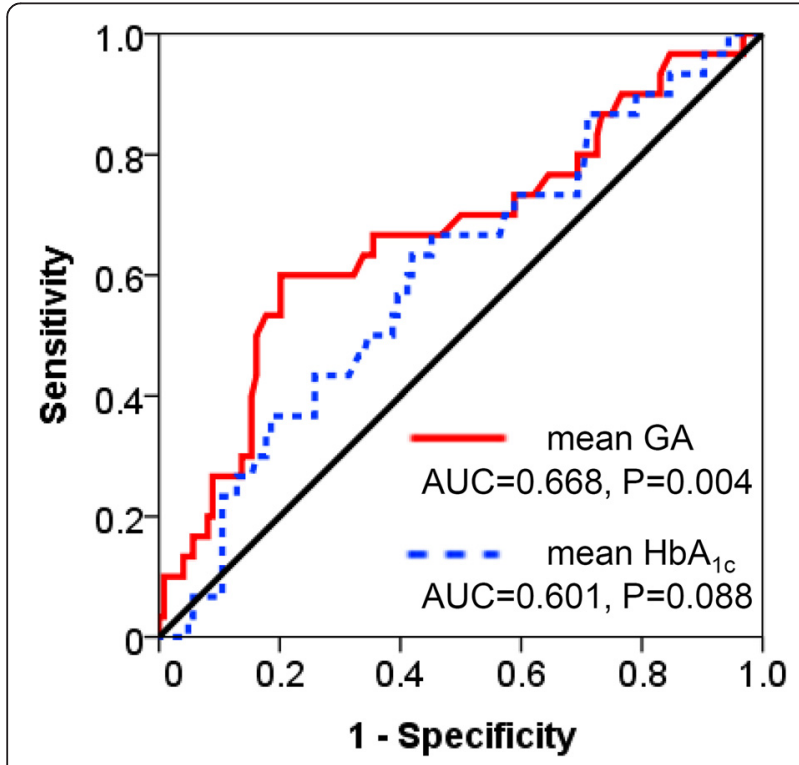

Fig. 2 Receiver operating characteristic curve of mean $\mathrm{HbA}_{1 c}$ and GA levels for predicting diabetic nephropathy progression and follow-up [86.9 (69.8-96.8) vs. 102.7 (83.6-112.8) $\mathrm{mL} / \mathrm{min} / 1.73 \mathrm{~m}^{2}, \mathrm{P}=0.030$ ] (Additional file 1: Table S1).

We used the multiple logistic regression model (model A) for carotid artery plaques and the multiple linear regression model (model B) for follow-up mean carotid IMT values to determine the clinically independent variables that were associated with carotid artery plaques. In both models, only age (model A: OR 1.20, 95 \% CI 1.051.36, $\mathrm{P}=0.007$, and model $\mathrm{B}$ : standardized $\beta=0.58, \mathrm{P}<$ $0.001)$ was significantly associated with CAA. In these models, glycemic indices, including mean GA levels and mean $\mathrm{HbA}_{1 \mathrm{c}}$, and renal function related variables were not significantly related to CAA (Table 3 ).

\section{Discussion}

This study focused on the association between glycemic indices and the progression of diabetic micro- and macrovascular complications in Korean subjects with T1D. The availability of longitudinal measurements for intermediate- and long-term glycemic indices, as well as for diabetic micro- and macrovascular complications, enabled us to investigate the associations between glycemic indices (GA levels and $\mathrm{HbA}_{1 \mathrm{c}}$ ) and the progression of DN and CAA in T1D. The longitudinal nature also conferred the availability of mean glycemic indices as time-dependent covariates.

Conventionally, DN is defined as a progressive kidney disease characterized by persistent albuminuria, increased blood pressure, and a continuous decline in GFR. It is a common cause of ESRD and has a high risk of cardiovascular morbidity and mortality [17, 18]. Although persistent albuminuria is a strong predictor for 
Table 3 Associations of the cardiovascular risk factors with carotid artery atherosclerosis in a subgroup of 54 subjects with T1D

\begin{tabular}{|c|c|c|c|c|c|}
\hline \multirow[b]{3}{*}{ Variables } & \multicolumn{3}{|c|}{ Model A } & \multicolumn{2}{|c|}{ Model B } \\
\hline & \multicolumn{3}{|c|}{ Presence of plaque at follow up } & \multicolumn{2}{|c|}{ Follow up IMT mean value } \\
\hline & OR & $95 \% \mathrm{Cl}$ & $\mathbf{P}$ & STD $\beta$ & $\mathbf{P}$ \\
\hline Age, per year & 1.20 & $1.05-1.36$ & 0.007 & 0.58 & $<0.001$ \\
\hline Sex $(0=$ female, 1 = male $)$ & 0.92 & $0.13-6.47$ & 0.933 & 0.01 & 0.915 \\
\hline Obesity $(0=$ no, $1=$ yes $)$ & 6.90 & $0.73-65.64$ & 0.093 & 0.13 & 0.251 \\
\hline Duration of diabetes, per 5years & 1.39 & $0.74-2.61$ & 0.301 & -0.02 & 0.886 \\
\hline Hypertension ( $0=$ no, $1=$ yes $)$ & 5.20 & $0.60-44.98$ & 0.135 & 0.03 & 0.801 \\
\hline Albuminuria at baseline ( $0=$ no, $1=$ yes $)$ & 4.61 & $0.60-35.57$ & 0.143 & 0.02 & 0.876 \\
\hline Baseline eGFR, per $1 \mathrm{~mL} / \mathrm{min} / 1.73 \mathrm{~m}^{2}$ & 1.05 & $0.97-1.12$ & 0.219 & -0.09 & 0.590 \\
\hline LDL-cholesterol, per $1 \mathrm{mg} / \mathrm{dL}$ & 0.98 & $0.94-1.02$ & 0.252 & 0.15 & 0.268 \\
\hline mean GA $(\%)^{*}$ & 0.43 & $0.09-2.00$ & 0.280 & -0.16 & 0.124 \\
\hline mean $\mathrm{HbA}_{1 c}(\%)^{*}$ & 0.53 & $0.21-1.36$ & 0.187 & 0.16 & 0.168 \\
\hline
\end{tabular}

Model A: multiple logistic regression analysis, Model B: multiple linear regression analysis

eGFR estimated glomerular filtration rate, IMT intima-media thickness, STD standardized

${ }^{*} z$-standardization of glycemic indices

DN progression, impaired GFR is possible in the absence of progression to proteinuria in T1D subjects with microalbuminuria [19]. Furthermore, the progression of albuminuria might be critical but not essential in CKD progression [20]. Based on these findings, in this study, we defined the progressed DN group as either deteriorated estimated GFR based CKD stages or the advent of microalbuminuria or progression of albuminuria stage $[21,22]$. In addition, based on our previous crosssectional study [23], we classified the available subjects into active and inactive CAA progression groups.

Considering the role of GA as a short-term (3-week) glycemic parameter, GA can reflect glucose fluctuation and postprandial glucose more sensitively than $\mathrm{HbA}_{1 \mathrm{c}}$ $[24,25]$. To investigate the association between the glycemic indices and the progression of diabetic micro- and macrovascular complications, we used the following analyses. To validate the reliability of glycemic indices in this study, we assessed correlations between $\mathrm{HbA}_{1 \mathrm{c}}$ and GA levels at baseline. As expected, $\mathrm{HbA}_{1 \mathrm{c}}$ and GA levels were highly correlated at baseline $(\mathrm{r}=0.631, \mathrm{P}<0.001)$. Next, we examined the association between glycemic indices and progression of DN and CAA. Recent studies reported that serum GA is closely associated with, or predicts, DN and diabetic retinopathy in patients with both T2D [26, 27] and T1D [11]. However, the clinical implications of GA on the presence or progression of CAA was not noted T1D patients [11] but was observed in T2D patients [7, 15]. Furthermore, GA but not $\mathrm{HbA}_{1 \mathrm{c}}$ was associated with coronary heart disease in the Chinese population with exclusion of T1D [28]. In a case-cohort subpopulation of the DCCT [11], $\mathrm{HbA}_{1 \mathrm{c}}$ and GA levels had similar associations with retinopathy and nephropathy, but only $\mathrm{HbA}_{1 \mathrm{c}}$ was significantly associated with cardiovascular disease. Selvin et al., also demonstrated the significant association of GA with incident CKD in subjects with both type 1 and 2 diabetes even after adjustment with $\mathrm{HbA}_{1 \mathrm{c}}$ [29], indicating that GA can work well for predicting microvascular complications [30]. This is supported by another study showing increased levels of GA in subjects with retinopathy [31]. This study has three main findings: first, diabetes duration fundamentally affected the progression of DN; second, albuminuria levels, not baseline CKD stage, were significantly related to DN progression; third, mean GA, but not mean $\mathrm{HbA}_{1 \mathrm{c}}$, were significantly associated with progression of DN. Regarding $\mathrm{CAA}$ as a macrovascular complication, $\mathrm{HbA}_{1 \mathrm{c}}$ and GA levels were not related to the progression of carotid IMT. Consistent with previous studies [21, 22], age was the only factor that was significantly associated with CAA in this study.

Although there was no association between $\mathrm{HbA}_{1 \mathrm{c}}$ and $\mathrm{DN}$, this does not imply that poor glycemic control does not affect diabetic microvascular complications. Considering glycemic control and the clinical outcomes in T1D, the DCCT/EDIC study clearly confirmed that patients with T1D in the intensive treatment group with lower $\mathrm{HbA}_{1 \mathrm{c}}$ levels had reduced risks of microalbuminuria and declines in GFR compared to patients in the conventional treatment group [2, 3, 5]. DN progression was assessed using multiple logistic regression models, and the association with mean $\mathrm{HbA}_{1 \mathrm{c}}$ was further attenuated once mean GA levels were also entered; however, mean GA levels might be augmented when $\mathrm{HbA}_{1 \mathrm{c}}$ was considered [11]. These findings suggest that GA measurements might be helpful in predicting $\mathrm{DN}$ in subjects with T1D.

With respect to the effects of GA on the progression of DN and CAA in T1D, we hypothesize that different complications might be affected by hyperglycemia. By 
pathophysiological, T1D is a disease caused by absolute insulin deficiency; however, the primarily underlying pathophysiologic mechanism of T2D is hyperinsulinemic insulin resistance [32]. Clinically, $\mathrm{DN}$ is more prone to glucotoxicity than insulin resistance. In addition, metabolic syndrome, primarily caused by insulin resistance, is a known risk factor for DN [33]. However, in this study, $\mathrm{BMI}$ and triglyceride levels were not related to $\mathrm{DN}$ progression. The low BMI of patients (Group I; mean BMI = $23.2 \mathrm{~kg} / \mathrm{m}^{2}$ and Group II; mean BMI $=22.4 \mathrm{~kg} / \mathrm{m}^{2}$ ) in our study population might account for the insignificant association between DN progression and variables for metabolic syndrome. Therefore, the statistical association of GA with the progression of DN but not with CAA is not surprising. We postulate that the clinical relevance of GA levels on the development of CAA in T1D might be in contrast to the presence of insulin resistance observed in T2D. Based on these findings, we postulate that glucotoxicity might be important for the progression of $\mathrm{DN}$, but insulin resistance might play a major role in the development of CAA regardless of diabetes type.

With respect to results on the relationship of glycemic indices with the progression of $\mathrm{DN}$ and CAA, our findings generally coincide with the data from previous studies; however, some conflicts remain. Possible explanations for our differing results are the differences in the baseline characteristics of patients and the longitudinal observation study design. The enrolled subjects had primarily adult-onset T1D (average age 46 years with 10 years of diabetes duration) with glycemia that was not well controlled (mean $\mathrm{HbA}_{1 \mathrm{c}}, 8.7 \%$ ). They were followed up for a median of 2.8 years to assess the progression of $\mathrm{DN}$ and CAA. Although mean creatinine $(0.8 \mathrm{mg} / \mathrm{dL})$ and estimated GFR $\left(97.1 \mathrm{ml} / \mathrm{min} / 1.73 \mathrm{~m}^{2}\right)$ levels were in the apparently normal range, this study included 8 subjects $(5 \%)$ with CKD (except for ESRD on dialysis). Because $\mathrm{HbA}_{1 \mathrm{c}}$ does not reflect blood glucose levels accurately in subjects with advanced renal disease [10], GA levels might more accurately reflect the glycemic status in these subjects. These differences in baseline characteristics and study design might account for the different results from previous studies.

This study had some limitations. First, the follow-up period was relatively short (2.8 years) and small number of T1D subjects which led to have not enough estimated power for this study (68\%). Second, we did not analyze the influence of smoking habits or medication status that could affect GA levels. Third, we did not measure blood pressure repeatedly; therefore, the effect of continuous blood pressure was not included. Despite these limitations, our study population consists primarily of patients with adult-onset T1D, which is not a common study population in the T1D research field. The tools for assessing glycemic indices $\left(\mathrm{HbA}_{1 \mathrm{c}}\right.$ and $\left.\mathrm{GA}\right)$ and diabetes complications (ACR and carotid IMT) are well documented. Moreover, this is the first longitudinal observation study for Asian subjects with T1D that examines the clinical relationship between glycemic indices and the outcomes of diabetic complications.

In summary, we investigated the association of various glycemic indices and the progression of DN and CAA in Korean subjects with T1D. Mean GA levels, rather than mean $\mathrm{HbA}_{1 \mathrm{c}}$, are more closely associated with the progression of DN. However, all glycemic indices were not associated with the progression of CAA. In conclusion, we suggest that GA levels, rather than $\mathrm{HbA}_{1 \mathrm{c}}$, are associated with $\mathrm{DN}$ progression and confer clinical relevance in the management of T1D. Well-designed prospective studies enrolling larger populations are warranted.

\section{Additional file}

Additional file 1: Table S1. Baseline characteristics of patients in which carotid intima-media-thickness was measured.

\section{Competing interests}

The authors declare that they have no competing interests.

\section{Authors' contributions}

Concept/design: B-WL, Y-hL, H-jY, BSC. Data analysis/interpretation: H-jY, Y-hL, THR, B-WL, HCL. Drafting article: H-jY, Y-hL, B-WL. Critical revision of article: B-WL, ESK, BSC, HCL. Statistics: H-jY, Y-hL, SRK. Data collection: H-jY, Y-hL, SRK. All authors read and approved the final manuscript.

\section{Author details}

'Department of Internal Medicine, Yonsei University College of Medicine, Seoul, South Korea. ${ }^{2}$ Severance Hospital, Seoul, Korea, 120-752. Institute of Vision Research, Department of Ophthalmology, Yonsei University College of Medicine, Seoul, Korea, 120-752.

Received: 10 February 2015 Accepted: 22 April 2015

Published online: 15 May 2015

\section{References}

1. Saisho $Y$, Tanaka $K$, Abe $T$, Kawai $T$, Itoh $H$. Lower beta cell function relates to sustained higher glycated albumin to glycated hemoglobin ratio in Japanese patients with type 2 diabetes. Endocr J. 2014;61(2):149-57.

2. The DCCT Research Group. The relationship of glycemic exposure ( $\mathrm{HbA} 1 \mathrm{c})$ to the risk of development and progression of retinopathy in the diabetes control and complications trial. Diabetes. 1995;44(8):968-83.

3. The DCCT Research Group. Sustained effect of intensive treatment of type 1 diabetes mellitus on development and progression of diabetic nephropathy: the Epidemiology of Diabetes Interventions and Complications (EDIC) study. JAMA. 2003;290(16):2159-67.

4. The DCCT Research Group. Effect of intensive therapy on the development and progression of diabetic nephropathy in the Diabetes Control and Complications Trial. Kidney Int. 1995;47(6):1703-20.

5. The DCCT Research Group. The effect of intensive treatment of diabetes on the development and progression of long-term complications in insulindependent diabetes mellitus. N Engl J Med. 1993;329(14):977-86.

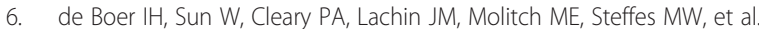
Intensive diabetes therapy and glomerular filtration rate in type 1 diabetes. N Engl J Med. 2011;365(25):2366-76.

7. Song SO, Kim KJ, Lee BW, Kang ES, Cha BS, Lee HC. Serum glycated albumin predicts the progression of carotid arterial atherosclerosis. Atherosclerosis. 2012;225(2):450-5.

8. Hwang YC, Jung CH, Ahn HY, Jeon WS, Jin SM, Woo JT, et al. Optimal glycated albumin cutoff value to diagnose diabetes in Korean adults: a 
retrospective study based on the oral glucose tolerance test. Clin Chim Acta. 2014;437:1-5

9. Huh JH, Kim KJ, Lee BW, Kim DW, Kang ES, Cha BS, et al. The relationship between $\mathrm{BMI}$ and glycated albumin to glycated hemoglobin (GA/A1C) ratio according to glucose tolerance status. PLoS One. 2014;9(2):e89478.

10. Kim KJ, Lee BW. The roles of glycated albumin as intermediate glycation index and pathogenic protein. Diabetes Metab J. 2012;36(2):98-107.

11. Nathan DM, McGee P, Steffes MW, Lachin JM. Relationship of glycated albumin to blood glucose and $\mathrm{HbA1C}$ values and to retinopathy, nephropathy, and cardiovascular outcomes in the DCCT/EDIC study. Diabetes. 2014;63(1):282-90.

12. Rewers M. Challenges in diagnosing type 1 diabetes in different populations. Diabetes Metab J. 2012;36(2):90-7.

13. Levey AS, Stevens LA, Schmid CH, Zhang YL, Castro AF, Feldman HI, et al. A new equation to estimate glomerular filtration rate. Ann Intern Med. 2009;150(9):604-12.

14. Kouzuma T, Usami T, Yamakoshi M, Takahashi M, Imamura S. An enzymatic method for the measurement of glycated albumin in biological samples. Clin Chim Acta. 2002;324(1-2):61-71

15. Moon JH, Chae MK, Kim KJ, Kim HM, Cha BS, Lee HC, et al. Decreased endothelial progenitor cells and increased serum glycated albumin are independently correlated with plaque-forming carotid artery atherosclerosis in type 2 diabetes patients without documented ischemic disease. Circ J. 2012;76(9):2273-9.

16. Touboul PJ, Hennerici MG, Meairs S, Adams H, Amarenco P, Bornstein N, et al. Mannheim carotid intima-media thickness and plaque consensus (2004-2006-2011). An update on behalf of the advisory board of the 3rd, 4th and 5th watching the risk symposia, at the 13th, 15th and 20th European Stroke Conferences, Mannheim, Germany, 2004, Brussels, Belgium, 2006, and Hamburg, Germany, 2011. Cerebrovasc Dis. 2012;34(4):290-6.

17. Hovind P, Rossing P, Tarnow L, Smidt UM, Parving HH. Progression of diabetic nephropathy. Kidney Int. 2001;59(2):702-9.

18. Park CW. Diabetic kidney disease: from epidemiology to clinical perspectives. Diabetes Metab J. 2014;38(4):252-60.

19. Perkins BA, Ficociello LH, Roshan B, Warram JH, Krolewski AS. In patients with type 1 diabetes and new-onset microalbuminuria the development of advanced chronic kidney disease may not require progression to proteinuria. Kidney Int. 2010;77(1):57-64.

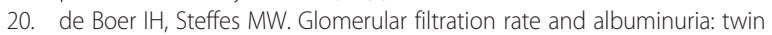
manifestations of nephropathy in diabetes. J Am Soc Nephrol. 2007;18(4):1036-7.

21. Viberti GC, Hill RD, Jarrett RJ, Argyropoulos A, Mahmud U, Keen H. Microalbuminuria as a predictor of clinical nephropathy in insulindependent diabetes mellitus. Lancet. 1982;1(8287):1430-2.

22. Levey AS, de Jong PE, Coresh J, El Nahas M, Astor BC, Matsushita K, et al. The definition, classification, and prognosis of chronic kidney disease: a KDIGO Controversies Conference report. Kidney Int. 2011;80(1):17-28.

23. Kim WJ, Kim KJ, Lee BW, Kang ES, Cha BS, Lee HC. The glycated albumin to glycated hemoglobin ratio might Not Be associated with carotid atherosclerosis in patients with type 1 diabetes. Diabetes Metab J. 2014:38(6):456-63.

24. Lee EY, Lee BW, Kim D, Lee YH, Kim KJ, Kang ES, et al. Glycated albumin is a useful glycation index for monitoring fluctuating and poorly controlled type 2 diabetic patients. Acta Diabetol. 2011;48(2):167-72.

25. Ogawa A, Hayashi A, Kishihara E, Yoshino S, Takeuchi A, Shichiri M. New indices for predicting glycaemic variability. PLoS One. 2012;7(9):e46517.

26. Pan J, Li Q, Zhang L, Jia L, Tang J, Bao Y, et al. Serum glycated albumin predicts the progression of diabetic retinopathy-a five year retrospective longitudinal study. J Diabetes Complications. 2014;28(6):772-8.

27. Kondaveeti SB DK, Mishra S, Kumar RA, Shaker IA. Evaluation of glycated albumin and microalbuminuria as early risk markers of nephropathy in type 2 diabetes mellitus. J Clin Diagn Res. 2013;7(7):1280-3.

28. Shen Y, Lu L, Ding FH, Sun Z, Zhang RY, Zhang Q, et al. Association of increased serum glycated albumin levels with low coronary collateralization in type 2 diabetic patients with stable angina and chronic total occlusion. Cardiovasc Diabetol. 2013;12:165.

29. Selvin E, Rawlings AM, Grams M, Klein R, Sharrett AR, Steffes M, et al. Fructosamine and glycated albumin for risk stratification and prediction of incident diabetes and microvascular complications: a prospective cohort analysis of the Atherosclerosis Risk in Communities (ARIC) study. Lancet Diabetes Endocrinol. 2014;2(4):279-88.
30. Cohen RM, Herman WH. Are glycated serum proteins ready for prime time? Lancet Diabetes Endocrinol. 2014;2(4):264-5.

31. Mukai N, Yasuda M, Ninomiya T, Hata J, Hirakawa Y, Ikeda F, et al. Thresholds of various glycemic measures for diagnosing diabetes based on prevalence of retinopathy in community-dwelling Japanese subjects: the Hisayama Study. Cardiovasc Diabetol. 2014;13:45.

32. Beckman JA, Creager MA, Libby P. Diabetes and atherosclerosis: epidemiology, pathophysiology, and management. JAMA. 2002;287(19):2570-81.

33. Thorn LM, Forsblom C, Fagerudd J, Thomas MC, Pettersson-Fernholm K, Saraheimo M, et al. Metabolic syndrome in type 1 diabetes: association with diabetic nephropathy and glycemic control (the FinnDiane study). Diabetes Care. 2005;28(8):2019-24.

\section{Submit your next manuscript to BioMed Central and take full advantage of:}

- Convenient online submission

- Thorough peer review

- No space constraints or color figure charges

- Immediate publication on acceptance

- Inclusion in PubMed, CAS, Scopus and Google Scholar

- Research which is freely available for redistribution 